\title{
The Bloxsom Air Lock: A Historical Perspective
}

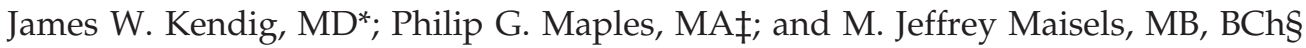

\begin{abstract}
In 1950, Allan P. Bloxsom (1901-1991), a pediatrician at the St Joseph Hospital in Houston, introduced his positive pressure oxygen air lock $(A L)$ for the delivery room resuscitation of the asphyxiated newborn. The infant's entire body was placed into a cylindrical steel chamber that was tightly sealed and infused with warmed humidified $60 \%$ oxygen. The positive pressure within the AL was cycled between 1 and $3 \mathrm{lb} / \mathrm{in}^{2}$ at 1-minute intervals to simulate the intrauterine pressures during the second stage of labor. Bloxsom developed the AL device in response to his hypothesis that the contractions of labor help to "condition: the infant for extrauterine survival.

Parmalee said that the AL "certainly locks the infant up, safe from meddlesome and unintelligent treatment." When clear plastic versions of the AL became commercially available, it received widespread use in delivery rooms and newborn nurseries throughout the United States. In 1953, Apgar and Kreiselman produced apnea in adult dogs using pentobarbital and a muscle relaxant, and found that the AL device was unsuccessful with the oxygenation and ventilation of the animals.
\end{abstract}

In 1954, Townsend in Rochester, New York, reported on his experience with the AL in $\mathbf{1 5 0}$ premature infants. He concluded that the AL should be "more accurately referred to as an oxygenator" and that, "the truly apneic infant cannot be maintained in a acyanotic state by the AL." The AL was finally subjected to the scrutiny of a randomized, controlled clinical trial that was published in 1956. Reichelderfer and Nitowski at Johns Hopkins randomized 171 infants to receive care in the $\mathrm{AL}$ or in an Isolette. Routine resuscitation, including positive pressure ventilation, was administered, as needed, to both study groups before placement into the AL or Isolette (Air Shields Inc, Hatboro, PA). They did not find any differences in the outcomes of the 2 study groups. By the mid 1950s, new information linking oxygen therapy and retrolental fibroplasia, led to a rapid decline in the use of the $\mathrm{AL}$, even before the publication of the randomized trial. Pediatrics 2001;108(6). URL: http://www.pediatrics. org/cgi/content/full/108/6/e116; Bloxsom air lock, neonatal resuscitation, prematurity.

ABBREVIATION. AL, air lock.

From the *Department of Pediatrics, Pennsylvania State College of Medicine, Hershey, Pennsylvania; $\ddagger$ Baker-Cederberg Museum and Archives, Rochester General Hospital, Rochester, New York; and §Department of Pediatrics, William Beaumont Hospital, Royal Oak, Michigan.

Presented, in part, at the Pediatric Academic Societies Annual Meeting; San Francisco, CA; May 1, 1999; and published in abstract form: Pediatr Res. 1999;45:306A

Received for publication May 24, 2001; accepted Sep 24, 2001.

Address correspondence to James W. Kendig, MD, Division of Newborn Medicine-H085, Department of Pediatrics, Milton S. Hershey Medical Center, Box 850, Hershey, PA 17033-0850. E-mail: jkendig@psu.edu PEDIATRICS (ISSN 0031 4005). Copyright $\odot 2001$ by the American Academy of Pediatrics.

\section{DEVELOPMENT OF THE POSITIVE PRESSURE OXYGEN AIR LOCK (AL) DEVICE}

I n 1950, Dr Allan Penny Bloxsom (1901-1991), a Houston pediatrician, introduced his positive pressure oxygen AL for the resuscitation and oxygenation of distressed newborns delivered by cesarean section. ${ }^{1}$ Dr Bloxsom was a highly respected general pediatrician who took a special interest in the distressed newborn infant long before neonatology became a recognized subspecialty. He received his medical degree from Johns Hopkins University and completed postgraduate training in pediatrics at the Harriet Lane Home in Baltimore, Maryland. He has been described as "a very accommodating gentleman, quietly industrious and retiring" (Dr J. A. Lucci, oral communication, August 1998). In 1942, he reviewed 100 consecutive infants delivered by cesarean section at the St Joseph's Infirmary (later referred to as the St Joseph's Maternity Hospital) in Houston, Texas, and reported that $42 \%$ of these infants required active resuscitation as compared with $18 \%$ of infants delivered by the vaginal route. ${ }^{2} \mathrm{He}$ recognized that maternal analgesics were important factors in causing neonatal depression, but he also hypothesized that the absence of uterine contractions, in the case of cesarean deliveries, had an adverse effect on the initiation of neonatal respirations. He proposed that the alternating uterine contractions during labor conditioned the fetal respiratory center to respond quickly after delivery. He also suggested that the uterine contractions had a direct stimulatory effect on the chest wall and lungs as the infant left the birth canal.

Bloxsom's positive pressure oxygen AL was designed to replicate the alternating pressure changes produced by the contracting uterus during labor. He constructed his original AL (Fig 1) by sawing an aluminum pressure cooker in half and welding in a center cylinder of sheet aluminum, resulting in a chamber 37 inches in length and 12 inches in diameter. Heating and humidification units and an array of pressure gauges, switches, and motors were added to create what must have been a noisy and frightening juggernaut in the premature nursery. The entire body of a distressed infant was placed into the AL device immediately after delivery, and the cylindrical chamber was infused with humidified $60 \%$ oxygen. The pressures within the chamber were then cycled between 1 and $3 \mathrm{lb} / \mathrm{in}^{2}$ at 1 -minute intervals to simulate the intrauterine contractions of labor. It is important to point out that Bloxsom's device was not a negative pressure ventilator or an "iron lung" device. 
Fig 1. Prototype of the positive pressure oxygen AL introduced by Dr Allen P. Bloxsom, Houston, Texas, 1950. From J Pediatr 1950;37:311. Used with permission.

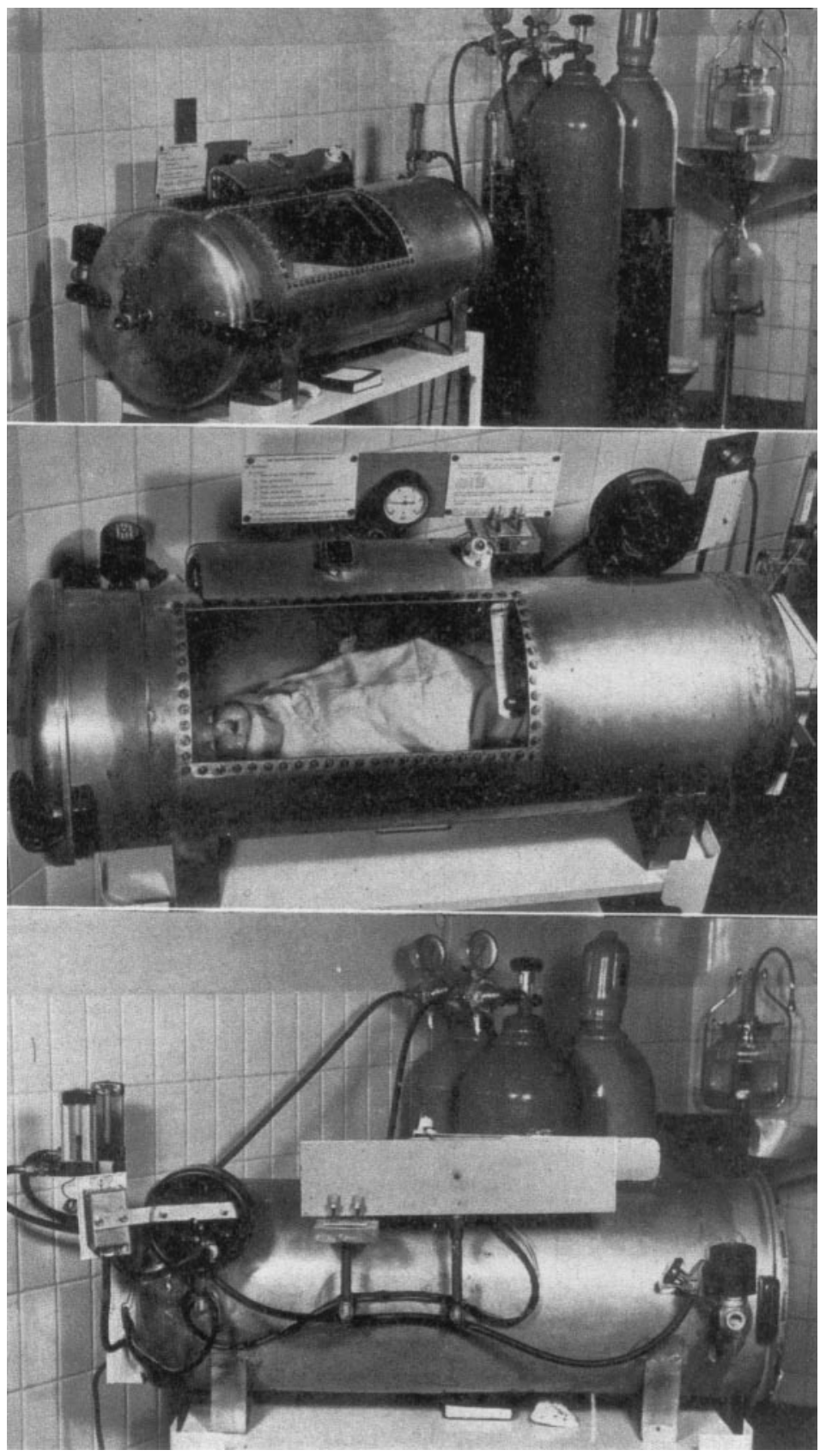

Bloxsom listed 7 specific advantages of his positive pressure AL (Table 1). In his original 1950 description of the AL, he reported that a total of 55 infants had been "processed in the lock in an attempt to habituate them to extrauterine conditions" with only 11 deaths. Soon after the development of the AL

TABLE 1. Purported Advantages of the AL

1. The promotion of bronchial drainage.

2. A more uniform alveolar aeration.

3. Increase of any absorption of oxygen thorugh the skin.

4. Relieving and protecting against atelectasis.

5. Provides a breathing exercise and improves muscle tone.

6. Combats acute pulmonary edema.

7. Provides favorable conditions for the diffusion and use of oxygen by the premature infant.

Bloxsom AP. J Pediatr. 1950;37:314. device, a commercial Plexiglas model was produced by the Loewenstern Corporation of Houston (Fig 2).

\section{UNCONTROLLED TRIALS AND EXPERIENCE WITH THE AL}

On June 29, 1950, Dr Bloxsom presented a paper about his new AL device before the Pediatrics Section of the 99th Annual Session of the American Medical Association in San Francisco, California. His paper entitled "Asphyxia Neonatorum-New Method of Resuscitation" and comments from the audience were published a year later in Journal of the American Medical Association. ${ }^{3}$ During the discussion period following Bloxsom's presentation, Dr Arthur H. Parmalee, a pediatrician from Beverly Hills, California, commented: 
Fig 2. Commercial Plexiglas version of the positive pressure oxygen AL. Arrival of the unit at the Dansville Memorial Hospital, Dansville, New York, June 1952; photo courtesy of James Gross and the Dansville Breeze, June 26, 1952.

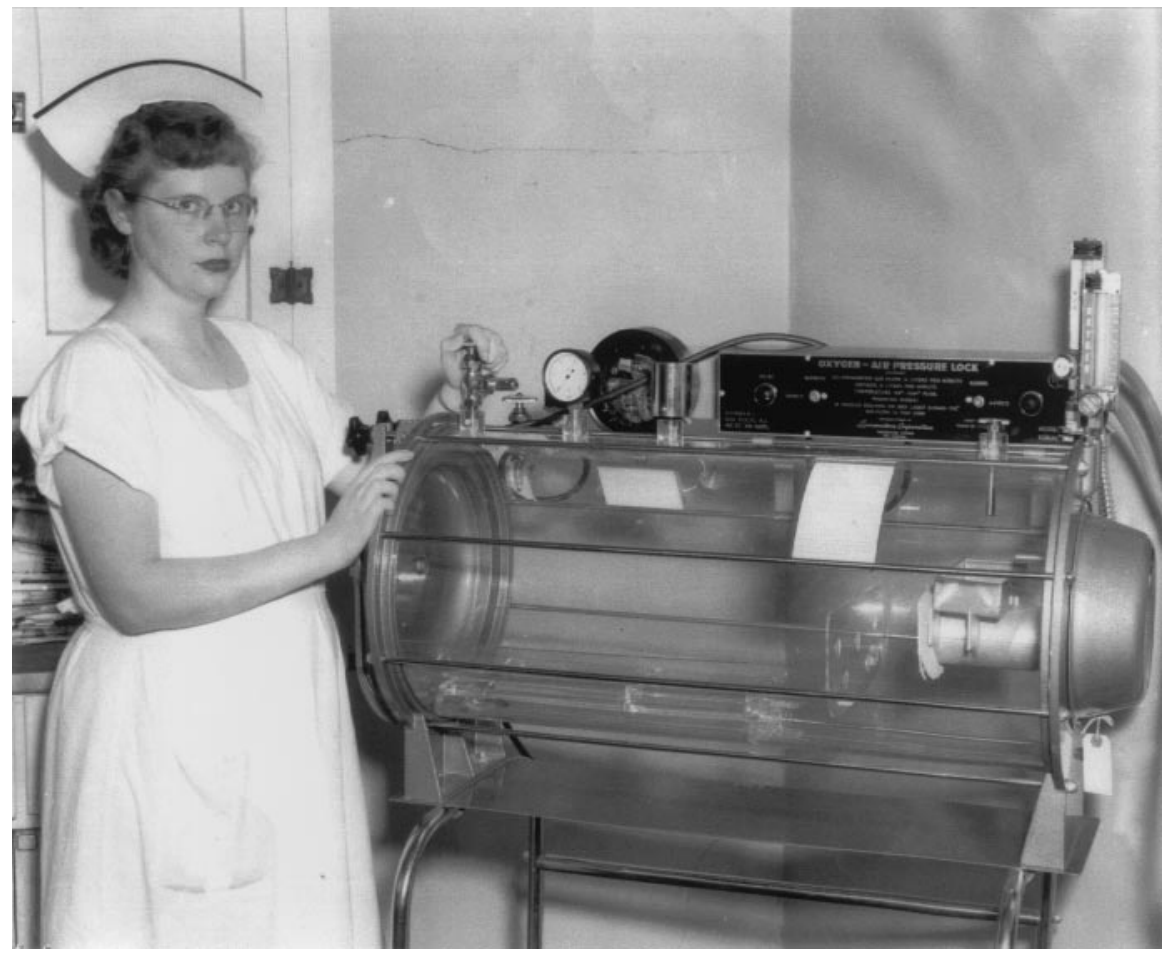

"Dr Bloxsom's method accomplishes at least 2 things that are advantageous to the infant. First, it favors absorption of oxygen through the skin and mucous membranes of the upper respiratory tract, sufficient perhaps to tide the infant over until such time as respirations may spontaneously begin. Second, it certainly locks the infant up, safe from meddlesome and unintelligent treatment."

Dr Robert A. Johnston of Houston remarked that: "With the use of the lock resuscitation, one can dispense, in practically all cases, with the tracheal catheter and its attendant danger."

The medical editor of Newsweek attended that convention and featured the Bloxsom $\mathrm{AL}$, complete with a photograph, in the July 10, 1950 issue. ${ }^{4}$ This article described the AL as "the Plexiglass Mother" and credited it with a $25 \%$ reduction in the infant mortality rate at the St Joseph Infirmary in Houston.

Two years later, Drs John Zelenik and Harry Prystowsky, ${ }^{5}$ obstetricians at the United States Army Hospital at Fort Benning, Georgia, reported their experience with 153 infants who were placed in the positive pressure oxygen AL between May 23, 1951, and January 12, 1952. They concluded that the AL "was a valuable adjunct in resuscitation and seemed to be lifesaving for the occasional depressed and/or premature infant."

In 1954, Dr Edward (Ted) H. Townsend, $\mathrm{Jr}^{6}{ }^{6}$ a practicing pediatrician and Director of the Regional Premature Center at the Rochester General Hospital in Rochester, New York, reported his experience with 150 infants placed in the AL during the preceding 18 months. He reported that 72 of the treated infants failed to show any demonstrable benefits from the AL device. He pointed out that the AL should be referred to as an "oxygenator" and that "the truly apneic infant cannot be maintained in an acyanotic state by the AL." Based on his studies with the AL, Townsend claimed that:

\begin{abstract}
"The improvement in color is not due to passive diffusion of oxygen into the infant's skin because of a higher pressure gradient; it is due to an improvement in general oxygenation of the infant. Proof of this lies in the fact that it is accompanied not only by an improvement in color but also by a reduction in the apparent degree of respiratory distress, which is in turn followed by an improvement in the infant's general clinical condition."
\end{abstract}

In a second paper published a year later, Townsend ${ }^{7}$ presented detailed clinical descriptions of 9 patients who improved after treatment in the AL. Here, he proposed that the AL was capable of promoting "antiatelectatic action." He attributed the observed clinical improvement to the "ability of the AL to induce expansion of collapsed segments of the pulmonary tissue."

In 1953, Drs Virginia Apgar and Joseph Kreiselman ${ }^{8}$ from the Department of Anesthesiology at the Columbia University College of Physicians and Surgeons, New York City, reported their laboratory studies with the Bloxsom AL device. They found that the device was ineffective for the resuscitation of adult dogs that were made apneic by the intravenous infusion of pentobarbital. They concluded:

\footnotetext{
"Indeed, the condition of any anoxic patient should be improved by placing him in an atmosphere of at least $50 \%$ oxygen, under a tension of more than $50 \mathrm{~mm} \mathrm{Hg}$ above atmospheric pressures. There is no evidence that any improvement in the infants is related to the alternating pressures simulating uterine contractions."
}

In an article published in 1954, Dr Bloxsom and Sister Mary Angelique ${ }^{9}$ from the St Joseph's Maternity Hospital responded to Dr Apgar's evaluation of their device as follows: "In January 1953, an adverse critical evaluation of the AL
from New York City appeared, based on attempts to make the
AL function as a barospirator for apneic adult dogs. Such a 
function, of course, was never intended or claimed for the AL."

They went on to report that the 48-hour mortality rate for term infants delivered at their hospital decreased from 63 per 10000 in 1949 to 37 per 10000 in 1952, a $41 \%$ reduction. They attributed this decline, in part, to the use of the AL. They also suggested that the AL pressure helped to induce a flattening of the alveolar cuboidal epithelial cells, providing a greater surface for the exchange of $\mathrm{O}_{2}$ and $\mathrm{CO}_{2}$.

Finally, in 1956, 6 years after the introduction of the Bloxsom AL device, a randomized, controlled clinical trail of the device was reported from Johns Hopkins Hospital by Reichelderfer and Nitowsky. ${ }^{10}$ Seventy-two infants were randomized to the AL and 71 to standard treatment in an Isolette brand of incubator. They found no differences in mortality rates or relief of respiratory distress between the 2 groups.

\section{EPILOGUE}

The Bloxsom AL device experienced a precipitous birth, a rapid acceptance and proliferation of usage, a rapid death, and now extinction. After its invention and evaluation by a single individual, the device rapidly captured the attention of both obstetricians and pediatricians and use of the device proliferated in the United States during the early and mid-1950s. Many hospitals viewed the device as a status symbol and local newspapers reported the acquisition and use of this most impressive device. The report in Newsweek magazine brought it to the attention of the general public.

Despite its bulky size and loud noise, the Bloxsom AL was readily accepted by the nurses who were in charge of the many new premature nurseries that were established in the 1950s. For very important reasons of infection control, the premature nursery nurses from that era viewed themselves as the guardians of the fragile preterm infants. Physicians, house officers, and parents were typically locked out of the premature nursery. Thus, these nurses viewed the AL device as an additional barrier with which they could exclude others and protect the fragile infants from "meddlesome treatment."

By the late 1950s, use of the Bloxsom AL rapidly declined, particularly after cases of retrolental fibroplasia were reported in preterm infants and the as- sociation between RLF and oxygen therapy was established. There were a few outposts where use of the AL continued into the early 1970s. One small hospital located in the mountains of northern Pennsylvania, for instance, was still using the device in 1972. The only remaining device known to the authors is located at the Medical Museum of the University of Iowa Hospital and Clinics, Iowa City, Iowa. In retrospect, the Bloxsom AL was an anomaly. Its introduction was not based on any previous technology and it did not lead to the development of similar new technological devices for the care of the newborn. However, it did call national attention to the concurrent development of the special care nurseries and their role in the treatment of distressed newborn infants.

\section{ACKNOWLEDGMENTS}

We thank Sister M. Monica LaFleur, CCVI, and her staff at the Sisters of Charity, Houston, for their invaluable assistance in searching the archives of the St Joseph Maternity Hospital and supplying us with many newspaper and magazine reports about the AL; James Gross, Noyes Memorial Hospital, Dansville, New York, for providing us with Fig 2; Dr Jospeh Lucci, Jr, of Houston, for his information about Dr Bloxsom; the staff of the University of Iowa Medical Museum, Iowa City, Iowa; and Jean Brockman and Nancy Campbell for their assistance in preparation of the manuscript. We also extend our appreciation to Dr Philip Wilson, Medical Historian in the Department of Humanities at the Pennsylvania State College of Medicine, Hershey, Pennsylvania, for his review of the manuscript.

\section{REFERENCES}

1. Bloxsom AP. Resuscitation of the newborn infant. Use of the positive pressure oxygen-air lock. J Pediatr. 1950;37:311-319

2. Bloxsom AP. The difficulty in beginning respiration seen in infants delivered by Cesarean section. J Pediatr. 1942;20:215-222

3. Bloxsom AP. Asphyxia neonatorum-new method of resuscitation. JAMA. 1951;146:1120-1124

4. Clark M. Doctors in conference. Newsweek. July 10, 1950

5. Zelenik JS, Prystowsky H. A study of one hundred fifty-three infants placed in the positive pressure oxygen-air lock. Am J Obstet Gynecol. 1952;64:1316-1321

6. Townsend EH Jr. The oxygen air pressure lock I. Clinical observations on its use during the neonatal period. Obstet Gynecol. 1954;4:184-193

7. Townsend EH Jr. The oxygen air pressure lock II. Antiatelectatic action in the neonatal period. Obstet Gynecol. 1955;5:678-686

8. Apgar V, Kreiselman J. Studies on resuscitation. An experimental evaluation of the Bloxsom air lock. Am J Obstet Gynecol. 1953;65:45-52

9. Bloxsom AP, Sister Mary Angelique. Neonatal infant mortality. Am J Obstet Gynecol. 1954;67:647-650

10. Reichelderfer TE, Nitowsky HM. A controlled study of the use of the Bloxsom air lock. Pediatrics. 1956;18:918-927 